\title{
Analysis of intonation in news presentation on television
}

Emma Rodero

Faculty of Communication, Pontificia University, Spain

https://doi.org/10.36505/ExLing-2006/01/0046/000046

\begin{abstract}
The effectiveness on the television communication is sustained on the handling of voice, which is the base of fundamental expression of the audio-visual contents. Consequently, the audience attention to the television message as well as under-standing and assimilating of it, will depend on a correct and expressive use of voice. These reasons guarantee the necessity to make an empirical investigation about the prosody form in which the news broadcasters on television use voice. Therefore, the actual communication is based on the results of a study in order to determine the intonation in broadcasters on television.
\end{abstract}

\section{Overview}

There are not many empirical investigations about TV broadcaster's intonation on television. Nevertheless, there is a wide bibliography in Spain which continuously referrers to the lack of effectiveness in the use of prosodic elements of journalists. Both experiments that have been carried out, and bibliographical references agree in signaling that there is a specific way of intonation of TV news which is, paradoxically, not the most appropriated, neither from a linguistic nor from a expressive point of view. In the presentation of news, journalists reproduce one singsong delivery pattern that represents the continuous repetition of a same structure: a circumflex intonation.

\section{Method}

According to this, the actual investigation tries to define the local movements of intonation which are more used in TV news to verify if this type of circumflex intonation in broadcaster's presentations does really take place. To prove this theory, the superficial phonological level of speech will be analyzed following the Aix-in Provence pattern.

The corpus of this research is composed by ninety utterances corresponding to the interventions of six broadcasters on television, fifteen utterances by each speaker, in the different news programs emitted by three main Spanish stations (two programs by a TV station). When selecting the definitive utterances for the analysis, two facts have been taken into account: utterances had to be declaratives and with similar extension.

ExLing 2006: Proceedings of 1st Tutorial and Research Workshop on Experimental Linguistics, 28-30 August 2006, Athens, Greece 
Once the corpus has been obtained, the analysis of the local movements is made by using the Praat program together with the Momel pattern of stylization, and the Intsint transcription system. In order to analyze the local movements, in the first place, the stylization and the transcription of each one of the utterances that compose the corpus has been made. Once the errors of detection of the system have been corrected by hand, and being the target points labeled by means of the Intsint tones, movements are computed by building groups of three targets, since it is our aim to characterize local manifestations. Target points have been entered considering if they were at the beginning (three first tones), at the middle or at the end of the analyzed utterance (three last tones), to be able to establish similar comparisons between the presentations of all broadcasters.

\section{Results}

Once collected the data, they have been analyzed with the software of statistical analysis SPSS. With this program, the calculation of the relative frequency of appearance of each one of the analyzed sequences has been made, and the percentage has been extracted.

In the analysis of the corresponding data at the beginning of the utterances, 25 combinations for the 90 cases have been obtained. The results reveal that most of the speakers start their utterances with the combination of MTD (almost a 27 percent), BHL (almost a 17 percent), BHD (a 12 percent) and MUS (an 11 percent). The rest of the groups are away from it yet. In the graphic, combinations which obtained just one percent of the total have been eliminated (18 combinations of 25)

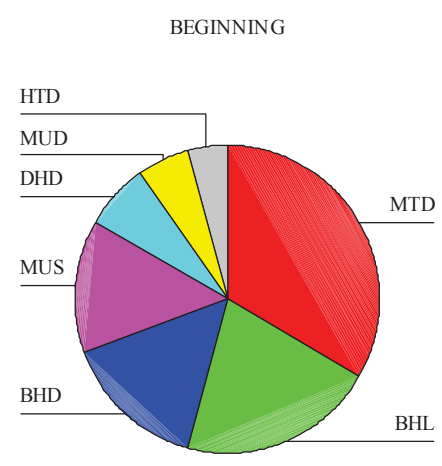

Figure 1: Percentage of frequency of appearance of pitch movements at the beginning of the utterance.

In the analysis of the segments corresponding to the middle of the utterances, 64 combinations for 1927 cases have been entered. The results 
indicate that most broadcasters use sequences DUD (28 percent), UDU (19 percent), ULU (17 percent) and LUL (16 percent). The rest of the groups are further from them. In the graph, combinations which obtained less than one percent do not appear (57 combinations of 64).

MIDDLE

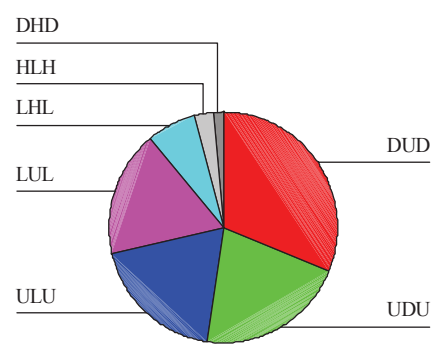

Figure 2: Percentage of frequency of appearance of pitch movements in the middle of the utterance.

Finally, the pitch movements at the end of utterances, in which 24 combinations for the 90 cases were obtained, have been analyzed. In this case, it is observed that the commonest grouping between speakers has been LTB (34 percent) followed by DTB (17 percent), DUD (14 percent) and LUL (11 percent). This descendent pattern takes place because the utterances are declaratives. The rest of them do not present significant differences. One percent is excluded from the graph (19 combinations of 24).

$$
\text { END }
$$

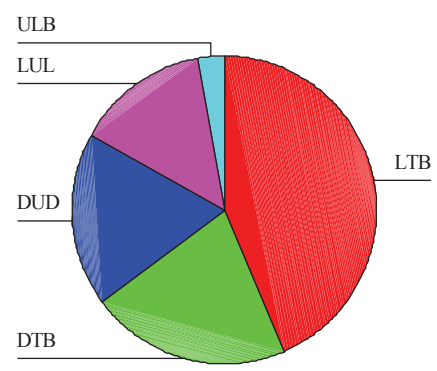

Figure 3: Percentage of frequency of appearance of pitch movements at the end of the utterance. 


\section{Discussion}

As we have verified in the results, every pitch combination that news broadcasters use on television, at the beginning, in the middle and at the end of their utterances, tend to present a F0 circumflex contour, although it varies the pitch level.

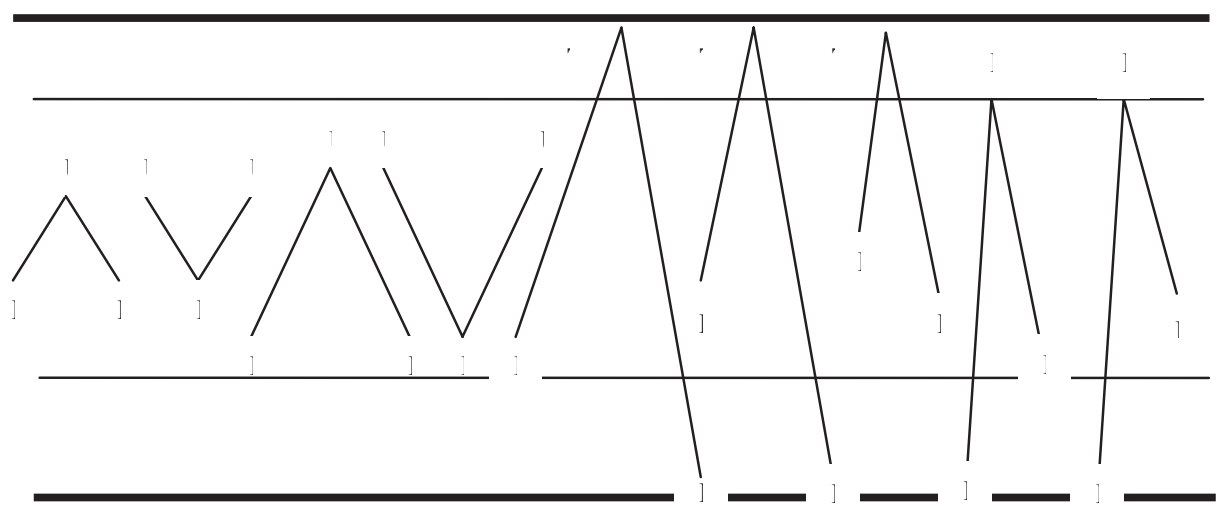

Figure 4: More frequent local movements.

It's certain that the results of the most frequent local movements do not throw too high percentages and that by just grouping the first options it is possible to collect data that are over fifty percent of the cases. Nevertheless, we must consider, firstly, that the number of possible combinations is very high and that most of them obtain pretty little frequencies of appearance. This fact contributes to show that the results are not so evident, since there is a great amount of groupings that appear only once.

Secondly, we must consider that, although there are different combinations which agglutinate the greater percentages, many of them are inverse or similar movements regarding acoustic impression, and they differ only in the ascendance or decline of pitch quantification. In conclusion, it is now considered that, at least in this analysis, the results gathered in the bibliography are according to the extracted empirical data in this study.

\section{References}

Hirst, D., Di Cristo, A. and Espesser, R. 2000. Level of representation and levels of analysis for the description of intonation systems. In Horne, M. (ed.), Prosody: Theory and Experiment, Dordrecht, Kluwer Academic Press, 51-87.

Louw, J.A. and Barnard E. 2001. Automatic intonation modelling with Intsint, Pretoria, Human Language Technologies Research Group, University of Pretoria.

Prieto, P. 2003. Teorías de la entonación, Barcelona, Ariel. 